\title{
The effects of anteromedial and dorsomedial thalamic lesions on passive avoidance and activity'
}

\author{
Lauren K. Gerbrandt \\ CLAREMONT GRADUATE SCHOOL
}

\begin{abstract}
Abstraet
Animals were tested for anteromedial and dorsomedial thalamic nucleus lesion effects on three activity tests and on a passive avoidance task. Insignificant effects were obtained on the activity tests and there was no correlation between activity scores and passive avoidance performance. The anteromedial thalamic lesioned group were retarded on passive avoidance performance while surgical controls and the dorsomedial thalamic nucleus lesioned group rapidly learned the avoidance response.

\section{Problem}

In a recent review of much of the neurological literature (Gerbrandt, 1964) it was concluded that the passive and active avoidance tasks represented fundamentally different problem solving situations in which the operation of distinct brain systems is critical. On the one hand, the passive avoidance task was used as a prototype for situations where the correct task solution was of a low probability of elicitation and in competition with a standing response of a higher probability of elicitation. The active avoidance task, however, was used as a prototype for situations necessitating the immediate elicitation of a high probability response where lower probability mediating responses might interfere. Lesions within a circuit similar to that suggested by Papez (1937) seemed to interfere with $\mathrm{raise}$ probability functions, while lesions within much of the medial and nonspecific thalamic nuclei and their projection fields seemed to interfere with $\mathrm{h}$ igh probability functions.

This investigation is intended to fill in two of the gaps which were left in the research relevant to the anatomical generalizations previously made. First, although it is well known that the anteromedial thalamic nucleus is an important link in the Papez circuit, this nucleus has not been specifically lesioned and the animal tested for functioning on a passive avoidance task. Second, the dorsomedial thalamic nucleus has been implicated as functioning on active avoidance tasks (Thompson, 1963) but these lesioned Ss were not tested for passive avoidance performance. In the present study Ss are lesioned in the dorsomedial and anteromedial thalamic nuclei and tested for passive avoidance performance.

\section{Method}

A total of 30 male hooded rats at 120 days of age were divided into groups of 10 each for surgical treatments. All Ss were anesthetized with Nembutal, stereotaxically mounted, and were surgically prepared for electrode trephining. The surgical control (SC) Ss were sutured and returned to their home cages at this point. The anteromedial (AMT) and dorsomedial (DMT) thalamic lesion groups were lesioned at 2 ma anodal current flowing for 10 and $20 \mathrm{sec}$, respectively. All Ss were then maintained for 120 days postoperatively until activity, flinch threshold, and passive avoidance testing.

The first activity test consisted of a simple home cage emergence situation where $\mathrm{S}$ was measured in latency of paw placement on the rim of its top-loading cage. A single trial was given by placing the cage in an unfamiliar surround, and $\mathrm{S}$ was allowed a maximum of $5 \mathrm{~min}$. for emergence. The second activity test was given the next day and consisted of a linear form of the closed-field test for exploratory activity. The activity measure consisted of the number of linear feet run during the single $2 \mathrm{~min}$. trial. The third activity test was given the following day and consisted of the amount of side-to-side movement exhibited by each $\mathrm{S}$ in a small tilt-cage apparatus during the single $5 \mathrm{~min}$. trial.

Flinch thresholds to shock were determined by the "staircase" psychophysical method (Dixon \& Massey, 1957) one week after the last activity measurement. The threshold score for each $\mathrm{S}$ consisted of the median current from 5 successive trials where $S$ changed from nonresponse to response, or vice versa. A constant current source was advanced from $0-1.25 \mathrm{ma}$ by 50 $\mu$ a steps and current was delivered only while $S$ had all four feet on the grid floor.

One day after flinch threshold testing, Ss were given an adaptation trial to the passive avoidance apparatus. The Ss were each placed on the $6 \times 6$ in masonite platform which was centrally mounted 2 in above the grid floor of the apparatus. After $30 \mathrm{sec}$. in the apparatus, each $\mathrm{S}$ was returned to its home cage until the learning trial $24 \mathrm{hr}$. later. On the learning trial, each $\mathrm{S}$ was again placed on the central platform and was punished with a $1.25 \mathrm{ma}$ constant current of $0.5 \mathrm{sec}$. duration upon stepping from the platform to the grid floor. Latency from platform placement to stepping off was measured. After another $24 \mathrm{hr}$. each $\mathrm{S}$ was given a retention trial where a latency of avoidance of $60 \mathrm{sec}$. was allowed. A week later histological verification of lesion placements was made with Toluidine Blue staining after freezing microtome sectioning at 50 microns. ${ }^{2}$

\section{Results and Diseussion}

In the passive avoidance task used in the present study the high probability response of stepping off the platform (Mdn. of $8 \mathrm{sec}$.) was in competition with the 
Table 1. Kruskal-Wallis Comparisons $(\underline{H})$ of Lesions on Activity Tests

\begin{tabular}{lccc}
\hline Groups Compared & Cage Bmergence & Txploratory & Tilt_Cage \\
\hline AMT vs. DMT & $1.33^{* *}$ & $2.47^{* * *}$ & $3.15 * * *$ \\
DMT vs. SC & $1.33^{* * *}$ & $.57^{*}$ & $.63^{*}$ \\
\hline
\end{tabular}

$* \mathrm{p}>.30 \quad * * \mathrm{p}>.20 \quad * * * \mathrm{p}>.10 \quad * * * * \mathrm{p}>.05$

initially low probability response of staying on the platform. After one trial of punishment for stepping off, however, 7 of the 9 control Ss had learned to the 60 sec. latency criterion. As expected, if a circuit similar to that of Papez functioned in raising the probability of staying on the platform, lesions in the AMT group result in continued exhibition of stepping off the platform (Kruskal-Wallis $\mathrm{H}=4.14 ; \mathrm{p}<.05$ ). The DMT lesions had no effect, as expected if a bias was produced towards raising the probability of staying on the platform $(\mathrm{H}=0.22 ; \mathrm{p}>.50)$. These results are similar to those of Thompson \& Langer (1963) where AMT lesions disrupted, while DMT lesions did not affect the reversal (raise-probability task) of position learning.

Alternative functional and anatomical hypotheses may be advanced about these data. First, it is possible that the lesions differentially affected the sensory input resulting from shock. A Kruskal-Wallis comparison of flinch thresholds to shock did not bear this out, however $(H=1.86 ; p>.30)$. Second, from a general "response inhibition" or "freezing" interpretation (McCleary, 1961), competing immobility producing mechanisms, if damaged, could result in increased activity, hence with interference of passive avoidance performance. From Table 1 it is apparent that none of the lesions produced significant activity differences on any of the tests used. Correlations between learning and cage emergence (Spearman $\left.r_{S}=.06 ; p>.05\right)$, exploration $\left(r_{S}=.04 ; p>.05\right)$, and tilt-cage activities $\left(r_{S}=.03 ; p>.05\right)$ are low and insignificant. Lastly, recent neurological evidence suggests that a system more complex than the "Papezcircuit" functions in raising the probabilities of re- sponses needed for task solution. Moore (1964) reports that septal and hippocampal lesions produce deficiencies on active avoidance retention, while Kimble (1964) reports no effect of a hippocampal lesion on a passive avoidance task similar to that used in this paper. Teitelbaum \& Milner (1963), however, have demonstrated that hippocampal lesioned Ss are deficient on this type of avoidance task. Since Kaada et al (1962) report no effect of hippocampal lesions on another type of passive avoidance task, while Isaacson \& Wickelgren (1962) report hippocampal lesions to affect this type of avoidance, it would appear that a further breakdown is necessary and possible in hippocampal-septal functions.

\section{References}

DIXON, W. J., \& MASSEY, F. J., JR. Introduction to statistical analysis. (2nd ed.) New York: McGraw-Hill, 1957.

GERBRANDT, L. K. Generalizations from the distinction of passive and active avoidance. Psychol. Rep., 1964, 15, 11-22.

ISAACSON, R. L., \& WICKELGREN, W. O. Hippocampal ablation and passive avoidance. Science, 1962, 138, 1104-1106.

KAADA, B. R., RASMUSSEN, E. W., \& KVEIM, O. Impaired acquisition of passive avoidance behavior by subcallosal, septal, hypothalamic, and insular lesons in rats. J. comp. physiol. Psychol, $1962,55,661-670$.

KIMBLE, D. P. The effect of hippocampectomy on passive avoidance learning. Science, in press.

McCleary, R. A. Response specificity in the behavioral effects of limbic system lesions in the cat. J. comp. physiol. Psychol., 1961, $54,605-613$.

MOORE, R. Y. Effects of some rhinencephalic lesions on retention of conditioned avoidance behavior in cats. J. comp. physiol. Psychol., $1964,57,65-71$.

PAPEZ, J. W. A proposed mechanism of emotion. Arch. Neurol. Psychiat., 1937, 38, 725-745.

TE ITELBAUM, H., \& MILNER, P. Activity changes following partial hippocampal lesions in rats. J. comp. physiol. Psychol., 1963, 56, 284-288.

THOMPSON, R. Thalamic structures critical for retention of an avoidance conditioned response in rats. J. comp. physiol. Psychol, $1963,56,261-267$.

\section{Notes}

1. This paper was presented in part at the meetings of the American Psychological Association, 1964, and was supported by research fellowship. MH-21,492 to the author.

2. Histological results may be obtained by writing to the author. 